\section{Comparing multisource harmonized forest types mapping: a case study from central Italy}

\author{
Matteo Vizzarri ${ }^{(1)}$, Ugo Chiavetta ${ }^{(2)}$, Gherardo Chirici ${ }^{(1)}$, Vittorio Garfi ${ }^{(1)}$, \\ Annemarie Bastrup-Birk ${ }^{(3)}$, Marco Marchetti ${ }^{(1)}$
}

The availability of common standardized geospatial information on composition, structure and distribution of forests is essential to support environmental actions, sustainable forest management and planning policies. Forest types maps are suitable tools for supporting both silvicultural and forest planning choices from local to global scale levels. For this reason local authorities may develop forest types maps independently, in which case a standardized/harmonized framework for their comparison and aggregation is essential. At the same time local forest types maps may not be directly related to pan-European forest resources assessments and classification systems. This paper presents results of the harmonization of four forest types maps available for central Italy. The process is based on a bottom-up approach aimed at maintaining the most detailed common nomenclature system across the different Regions. The final results, in terms of forest types area, are compared with several independent sources of information: (i) two forest maps, one developed at national level on the basis of the Corine Land Cover 2006, and one for high resolution forest / non forest classification developed at pan-European level; and (ii) two sample based inventories: the Italian National Forest Inventory (INFC) and the Italian Land Use Inventory (IUTI). The results show that the proposed bottomup harmonization approach is a suitable tool to guarantee the integrity and homogeneity of local forest types nomenclature systems, and to integrate such local data with European standards.

Keywords: Forest Categories, Forest Types, Central Italy, Forest Area Estimation, Forest Nomenclature Systems, Forest Resources Classification, Forest Resources Mapping

\section{Introduction}

\section{Forest types}

Information on the distribution and characteristics of forest ecosystems is essential to support decision makers for a correct implementation of Sustainable Forest Management (SFM) and to optimize the provisioning of ecosystem services (Köhl et al. 2006). The use of standardized multi-scale nomenclature systems to describe the characteristics of forests is necessary to facilitate the integration of forest ecosystem planning, usually developed for large regional and continental areas, with forest management strategies developed at local level.

In such a framework the Forest Types (FTs) approach, originally developed in Italy two decades ago (Del Favero et al. 1990), is nowadays frequently adopted as a nomencla-
(1) Dipartimento di Bioscienze e Territorio (DiBT), Università degli Studi del Molise, Contrada Fonte Lappone, I-86090 Pesche, Isernia (Italy); (2) Consiglio per la ricerca e la sperimentazione in Agricoltura, Forestry Research Centre, v.le S. Margherita 80, I-52100 Arezzo (Italy); (3) European Environmental Agency, Kongens Nytorv 6, DK-1050 Copenhagen (Denmark)

@ Matteo Vizzarri (matteo.vizzarri@unimol.it)

Received: Sep 20, 2013 - Accepted: Feb 26, 2014

Citation: Vizzarri M, Chiavetta U, Chirici G, Garfì V, Bastrup-Birk A, Marchetti M, 2015. Comparing multisource harmonized forest types mapping: a case study from central Italy. iForest 8: 59-66 [online 2014-06-17] URL: http://www.sisef.it/iforest/contents/? id=ifor $1133-007$

Communicated by: Luca Salvati ture system for forest classification, since FTs can be directly related to silvicultural treatments and other ecological forest characteristics. A FT can be described as "a category of forest defined by its composition, and/or site factors (locality), as categorized by each country in a system suitable to its situation" (Canadian Forest Service 1995). This concept embraces all forest classification systems that allow a hierarchical assessment of forest stands through a synoptic evaluation of both vegetation composition (floristic and/or phytosociological) and ecological-silvicultural characteristics (Del Favero 2000).

FTs classification systems are usually organized according to a hierarchical structure: the main level is based on types which are grouped in categories usually on the basis of the main dominant tree species, types may be optionally further divided in subtypes or variants.

FTs are commonly assessed at stand level to be consistent with the scale of forest resource management units (Corona et al. 2004), but they are also frequently used as a system of nomenclature of forest maps created on the basis of remotely sensed data.

At a continental level, the European Environmental Agency (EEA 2006) published a first version of a European Forest Types (EFTs) system that was adopted by Forest Europe/UNECE/FAO (2011) for reporting a large set of SFM indicators for European countries. The EFTs were recently revised with minor adjustments in Barbati et al. (2014).

\section{Forest types area assessment in Italy}

Forest resource assessments can be applied using two principal methodologies: (i) forest inventory based on the investigation of a small part of the interested region in the form of a sample, the result is an aggregated statistic for the whole region or for a subpart of it; and (ii) forest mapping, that is nowadays based on the elaboration of remotely sensed data to investigate the entire region of interest. The result is a geographical depiction of the location of forest and related attributes (Corona 2010).

Currently there are several independent sources of information available in Italy for estimating forest area, which are all based on different systems of classification. Following is a brief description of the state of the art in this field.

The second Italian National Forest Inventory (INFC 2005 - Inventario Nazionale delle Foreste e dei serbatoi forestali di Carbonio) provided the estimation of forest area on a nomenclature system structured into 17 forest categories (FCs), further divided in 91 sub-categories (Sub-Cs - Tabacchi et al. 2007). INFC was based on a three-phase 
Tab. 1 - Main characteristics of the local FTs maps used in the study.

\begin{tabular}{lcccc}
\hline Region & $\begin{array}{c}\text { Regional area } \\
\text { (ha) }\end{array}$ & $\begin{array}{c}\text { Reference } \\
\text { year }\end{array}$ & $\begin{array}{c}\text { Forest area } \\
\text { (ha) }\end{array}$ & $\begin{array}{c}\text { Percent of } \\
\text { forest cover }\end{array}$ \\
\hline Abruzzo & 1083004 & 2005 & 454017 & 41.9 \\
Lazio & 1722620 & 2007 & 619575 & 35.9 \\
Marche & 972860 & 2001 & 256620 & 26.3 \\
Molise & 446107 & 2004 & 157609 & 35.3 \\
\hline
\end{tabular}

sampling design: the first phase was carried out on the basis of digital aerial orthophotos on a total of approximately 300000 sampling units distributed on the basis of a tessellated random sampling, while the second and third phases were based on field work The forest definition adopted was the same used by FAO (2000).

More recently the Italian Land Use Inventory (IUTI - Inventario dell'Uso delle Terre in Italia) sought to estimate the area coverage of six land use categories (including "Forest land" - Corona et al. 2012). The IUTI project, according to the GPG-LULUCF guidelines (Romano et al. 2011), was carried out by manual classification of sampling units distributed on the basis of a tessellated random sampling (Fattorini \& Tabacchi 2004) superimposed on digital aerial orthophotos. The forest definition adopted in IUTI was the same as that of the INFC.

Both INFC and IUTI projects provided estimates, with confidence intervals, at country level and for NUTS2 administrative units (called "Regions" in Italy).

In central Italy, FTs maps are currently available for many Regions: Tuscany (Hofmann et al. 1998), Marche (IPLA 2001, Pesaresi et al. 2007), Lazio (Chirici et al. 2014), Abruzzo (Corona et al. 2001) and Molise (Garfì \& Marchetti 2011). Those from Marche, Lazio, Abruzzo and Molise were all developed using the same methodology and adopted the same forest definition as that used by INFC and IUTI, with the same scale (1:10 000) and the same Minimum Mapping Unit (MMU) of 0.5 ha. But the four maps adopted different nomenclatures all based on forest categories subdivided in types.

In Italy, the Corine Land Cover (CLC) 2000 and 2006 maps were developed refining the original European nomenclature system. The standard forest classes (broadleaved/coniferous/mixed) were detailed in 14 FCs based on dominant species. The CLC maps were developed by manual delineation of multispectral satellite images, with a scale of 1:100 000 and a MMU of 25 ha (Sambucini et al. 2010).

At pan-European level, the European Commission's Joint Research Centre (JRC) developed FMAP2006 and FTYP2006, a high resolution (pixel of $25 \mathrm{~m}$ ) forest, non-forest map and a forest type map derived from the IMAGE2006 database, MODIS data and the
CLC2006 map as training data (Kempeneers et al. 2011).

It is important to note that in Italy the vegetation was recently classified by Blasi (2010) into 240 series, 37 vegetation mosaics, 39 geo-series (sigmeta), which were then reassembled into 279 legend classes. The system resulted from the integration of two processes: (i) land units obtained through a hierarchical land classification; and (ii) vegetation series defined using phytosociological field data and the expert knowledge of the relationships between present vegetation communities, environmental factors and vegetation dynamics.

Finally, forest habitats can be also classified according to the CORINE habitat nomenclature system that is based on a total of 230 classes (Amadei et al. 2003).

\section{The aim of this contribution}

The topic of contrasting different information sources for forest area assessment is relevant both for the scientific community and for forest managers and decision-makers. Such an interest was clearly demonstrated at a pan-European level by Seebach et al. (2011) when country level forest area estimates were calculated on the basis of diffeand CLC maps.

Since the different monitoring projects available in Italy (INFC, IUTI, CLC and JRC forest / non-forest map, local forest other, the problem of harmonizing the different nomenclature systems across the different administrative Regions was extremely relevant. In the framework of the approach recently proposed by Ståhl et al. (2011), the comparison of forest information acquired on the basis of different definitions can be approached through the use of "harmonization bridges" (McRoberts et al. 2009). The harmonization approach can be seen as a method to maintain the characteristics of local data which are based on different definitions and methods enabling their comparability at a higher hierarchical level on the basis of commonly agreed reference definitions.

The aim of this paper is to first present the development of bridges to create a harmonized high resolution FTs map (scale 1:10 000, MMU of 0.5 ha) based on local maps available in a study area in central Italy that inrent sources of information, including NFIs maps) were developed independently of each cludes the administrative Regions of Marche, Abruzzo, Lazio and Molise. This approach produced on a harmonized nomenclature system with relationships with other existing systems: INFC, CLC06, EFTs, vegetation of Italy (Blasi 2010) and CORINE biotopes. Subsequently we compared the resulting harmonized FTs area estimations based on local high resolution forest maps with those resulted from other independent sources: the Italian National Forest Inventory (INFC 2003), and the CLC06 classes (Sambucini et al. 2010). The same test was repeated comparing forest / non-forest area estimations, including the results obtained from IUTI and the JRC map.

\section{Materials and methods}

\section{Materials}

The study area covers a total of $42246 \mathrm{~km}^{2}$ and includes four administrative Regions located in central Italy: Marche, Abruzzo, Lazio, and Molise. The elevation ranges from sea level to the top of Gran Sasso (2914 m a.s.l.), the highest peak of the Apennine mountain range. The climate in the study area is mainly Mediterranean and temperate with precipitations concentrated in spring and autumn.

For the study area, four regional high resolution forest maps were used. The maps were originally produced at a scale of 1:10 000, with a MMU of $0.5 \mathrm{ha}$, and are all based on the manual delineation of digital orthophotos acquired in the period 2001-2007, integrated with field assessment (Tab. 1).

The formal accuracy of these maps is unknown but they are all released with a certified thematic accuracy of at least $85 \%$, according to the well-known international standard originally proposed by Anderson et al. (1976). The four maps adopt the same forest definition from the FAO (2000) but different nomenclature systems: in Abruzzo 32 FTs grouped in 12 FCs (Corona et al. 2001); in Lazio 36 FTs grouped in 16 FCs (Chirici et al. 2014); in Marche 42 FTs grouped in 11 FCs (IPLA 2001); in Molise 40 FTs and 14 FCs (Garfi \& Marchetti 2011).

The CLC06 forest map and the 2006 JRC high resolution forest / non-forest map, both available on-line, were clipped to the extent of the four administrative Regions. Finally the aggregated statistics of forest area for the different FCs of the National Forest Inventory (INFC - Gasparini et al. 2010) and for the forest area from the IUTI project were acquired.

\section{Methods}

The methodology adopted to harmonize the FTs nomenclature systems of the different dataset available in the study area follows a bottom-up approach, from local to European level, and from FTs to FCs. Fig. 1 presents 
an overview of the whole methodological framework adopted to harmonize the FTs systems.

Firstly the four FTs systems from the high resolution forest maps of Marche, Abruzzo, Lazio and Molise were compared and a new reference system, called Harmonized Forest Types Nomenclature System (HFTNS), was created for the study area. The new reference HFTNS was organized in Harmonized Forest Types (HFTs) grouped in Harmonized Forest Categories (HFCs). The HFTNS was built by comparing and assessing the correspondences among the diagnostic characters of the FTs nomenclature systems implemented in each one of the four investigated Regions (Del Favero \& Lasen 1993, Del Favero 2010). Within the framework of the general harmonization rules presented in Ståhl et al. (2011), two principles were followed: (i) to permit the unambiguous reclassification of regional FTs in the new HFTs; (ii) to develop the most detailed nomenclature systems preserving as far as possible the detail of the original four nomenclature systems.

Under a logical point of view, the different nomenclature systems were firstly aggregated with a merge (union) operator. The resulting system was then simplified by aggregating those local forest types that had the same diagnostic characters. Finally the types were aggregated in categories.

For each one of the resulting HFTs a unique correspondence was found with: (i) the FCs of the INFC nomenclature system; (ii) the EFTs sensu Barbati et al. (2014); (iii) the CLC06 classes; (iv) the vegetation classes from Blasi (2010); and (v) the CORINE biotopes.

Each polygon of the four local high resolution forest maps was reclassified according to the HFTNS, and the resulting harmonized maps were merged.

The forest area for the four different administrative Regions was calculated on the basis of: (i) IUTI; (ii) INFC; (iii) CLC06; and (iv) the mosaic of regional HFTs maps.

By analyzing the bridges between the HFTNS and the other nomenclature systems it was possible to create a common simplified nomenclature to compare the forest area for the different classes on the basis of: (i) INFC; (ii) CLC06; and (iii) the mosaic of regional HFTs maps.

\section{Results}

The first results of this test are the bridges created to reclassify FTs and FCs across the different nomenclature systems: those locally available in the four administrative Regions; the system adopted by the INFC; the Italian implementation of the CLC06; the EEA EFTs sensu Barbati et al. (2014); the Blasi (2010) system used to describe the vegetation of Italy; and finally the CORINE biotopes.

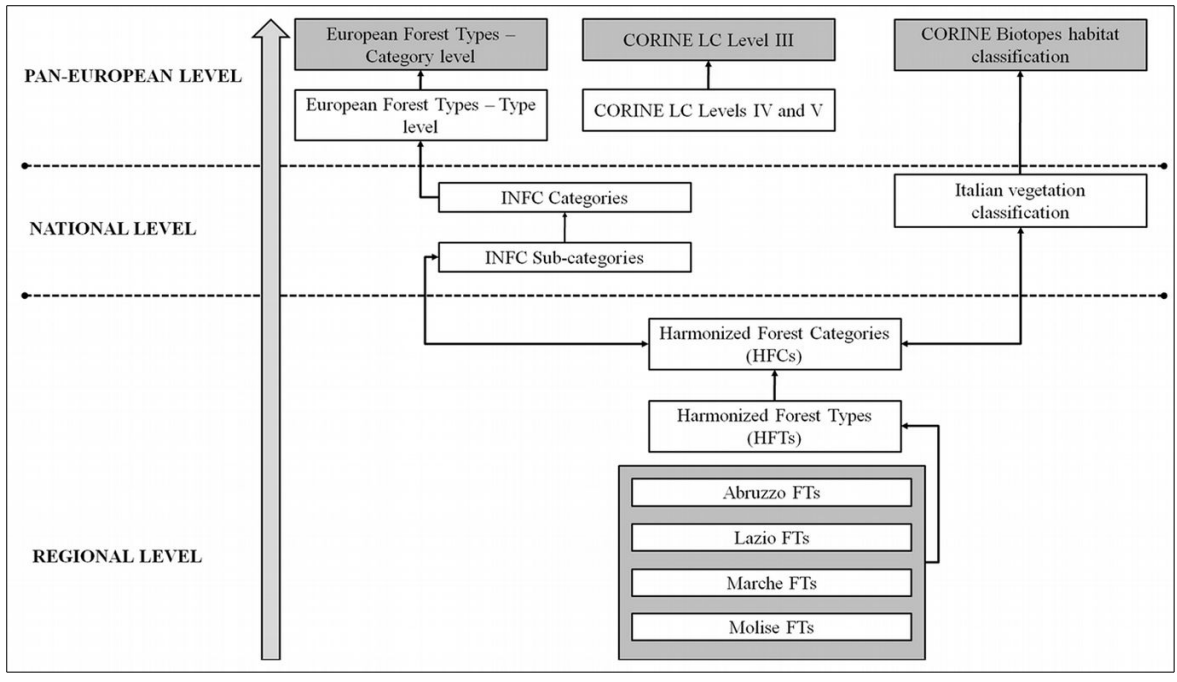

Fig. 1 - Bottom-up approach adopted to harmonize FTs nomenclature systems. The flowchart shows the bottom-up approach adopted to harmonize FTs nomenclature systems at regional, national and European levels. From bottom to top, the arrows show the corresponding directions followed to harmonize the different FTs nomenclature systems at each step.

In Appendix 2 we provide the bridges in terms of the correspondences between the HFTNS and (i) CLC06 classes, (ii) EFTs, and (iii) INFC FCs and Sub-Cs, while in Appendix 3 those for (i) the syntaxonomic classes (sensu Blasi 2010), and (ii) the CORINE biotopes.

The second set of results concerns the comparison of forest areas by FTs.

The HFTNS developed by harmonization of the different FTs nomenclature systems resulted in 42 HFTs grouped in 16 HFCs. In Appendix 3 the correspondences between the HFTs and the original FTs from the regional maps is presented.

Merging the four FTs maps based on the new HFTNS in the study area we produced a new harmonized map (Fig. 2).

In Fig. 3 the area calculated on the basis of the dominant FCs was recalculated from the new harmonized map of Fig. 2.

\section{Results in terms of forest / non-forest area}

The forest area in the study area was calculated on the basis of the five available datasets (Fig. 4).

The design based forest area estimations by IUTI and INFC tends to be very similar (1 470564 ha and 1432485 ha, respectively), the difference for both is within their relative confidence interval. The forest area from the HFCs and the JRC forest / nonforest maps appears to be higher (1 487822 ha and 1552179 ha, respectively), while that from CLC06 appears lower (1 303730 ha).

When the same comparison is carried out separately for the four administrative Regions (Fig. 4), the following main results can be denoted: (i) the sampling based estimations (IUTI and INFC) are never within their relative confidence intervals; (ii) in all Regions with the exception of Lazio, the INFC estimation is lower than that from IUTI; (iii) the forest area from CLC06 always tends to be lower with respect to IUTI and INFC; (iv) the forest area from the JRC forest / nonforest map always tends to be higher when compared to IUTI and INFC; (v) the forest area from HFCs maps tend to be higher than IUTI and INFC in all the Regions, with the exception of Marche; (vi) in Molise a relatively consistent agreement is shown across the different datasets.

\section{Results in terms of forest types area}

On the basis of the HFTs map (Fig. 2), the $37 \%$ of the total forest area is covered by forests dominated by Turkey and downy oaks (Quercus cerris and Q. pubescens), mainly in meso-xerophilous conditions, with a total of more than 547000 ha. Beech forests (Fagus sylvatica), with 254792 ha (about the 17\% of the total), are the second most important HFC. They are mainly located in mountainous sites in Abruzzo and Molise. Other broadleaved forests in mesophylous conditions dominated by hop-hornbeam and flowering ash (Ostrya carpinifolia and Fraxinus ornus) cover almost 300000 ha $(13 \%$ of the total). Other FCs dominated by coniferous in mountainous (Pinus nigra and Abies alba) and Mediterranean conditions (Pinus pinea and Pinus pinaster), chestnut (Castanea sativa), evergreen oaks (Quercus ilex and Q. suber) and riparian formations, all range between 4 and 5\%. Forest plantations are negligible and finally Other Wooded Land (OWL) covers almost 


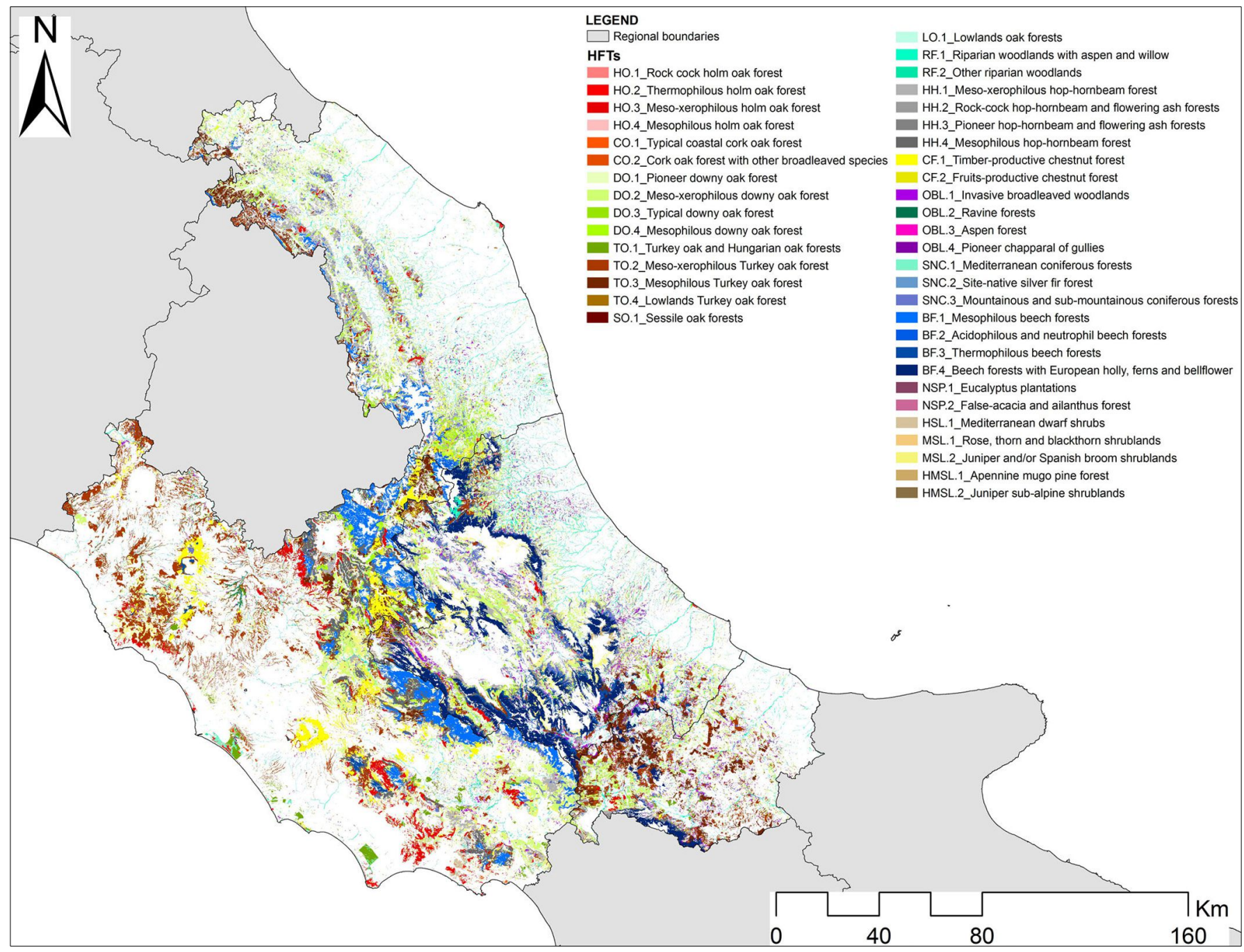

Fig. 2 - HFTs map of Central Italy. Thematic legend lists all HFTs as obtained through the harmonization process.

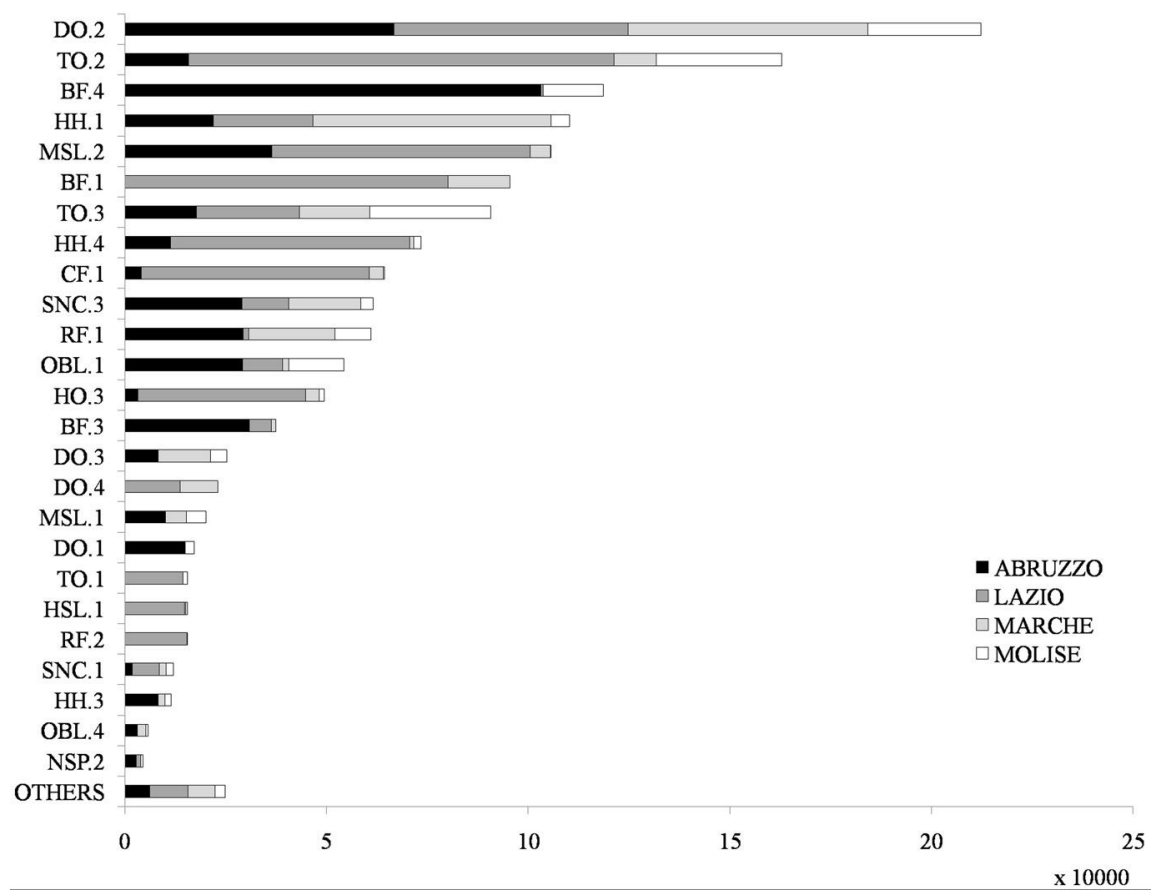

Fig. 3 - HFTs area (ha) for each region in central Italy. See Appendix 1 for the HFTs label definition. 
Fig. 4 - Forest area estimates (ha) from HFCs map, CLC06 map, IUTI, INFC and JRC for all regions in central Italy. Error bars represent SE of IUTI and INFC, respectively.
150000 ha $(10 \%)$.

To make possible the comparison of FCs across the three available sources (HFTs map, CLC06 map, and INFC statistics), we used an aggregated nomenclature system based on nine macro categories (Tab. 2).

The results of the comparison are presented in Fig. 5. For only two classes, beech (BF)

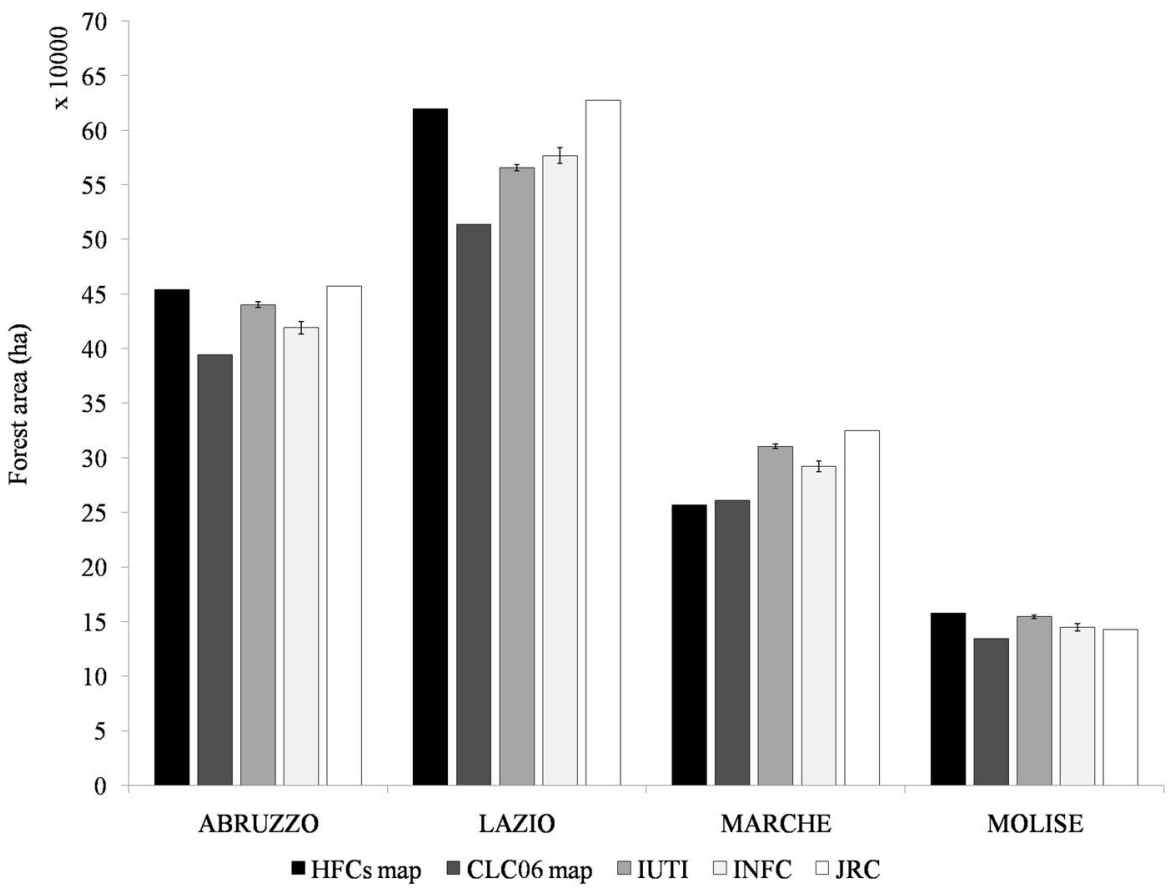

and deciduous oaks (DO SO LO TO), the lower for deciduous oaks by $6 \%$. Together areas from both maps (HFCs and CLC06) these two classes, on the basis of INFC, repwere quite consistent with the official stati- resent more than the $50 \%$ of the total forest stics from INFC but were outside of their and OWL area. In addition, three classes: confidence intervals. For both classes, the chestnut (CF), evergreen oaks (HO CO) and figures from the HFCs map were higher by site native coniferous forests (SNC), showed $11 \%$ and $9 \%$ respectively, while the CLC06 a relatively consistent area estimation, but figures for beech was higher by $7 \%$, and when combined based on the INFC, they

Tab. 2 - Aggregated nomenclature system used to compare HFCs, INFC and CLC06. For each one of the nine aggregated classes the corres pondence with the different sources is provided. See Appendix 2 for a more detailed description of the different classes.

\begin{tabular}{|c|c|c|c|c|}
\hline $\begin{array}{l}\text { Aggregated } \\
\text { HFCs }\end{array}$ & HFCs & INFC & $\begin{array}{l}\text { CLC06 Code } \\
\text { (National level) }\end{array}$ & $\begin{array}{l}\text { CLC06 } \\
\text { Classes description }\end{array}$ \\
\hline$\overline{\mathrm{BF}}$ & $\mathrm{BF}$ & $\mathrm{BF}$ & $\begin{array}{c}3.1 \cdot 1.5 \\
(3.1 \cdot 3 \cdot 1.5)\end{array}$ & Forests dominated by beech \\
\hline$\overline{\mathrm{CF}}$ & $\mathrm{CF}$ & $\mathrm{CF}$ & $\begin{array}{c}3.1 .1 .4 \\
(3.1 \cdot 3 \cdot 1.4)\end{array}$ & Forests dominated by chestnut \\
\hline$\overline{\mathrm{HO} \_\mathrm{CO}}$ & $\begin{array}{l}\mathrm{HO} \\
\mathrm{CO}\end{array}$ & $\begin{array}{l}\mathrm{HO} \\
\mathrm{CO}\end{array}$ & $\begin{array}{c}3.1 .1 .1 \\
(3.1 .3 .1 .1)\end{array}$ & $\begin{array}{l}\text { Forests dominated by oaks and other evergreen broadleaved species } \\
\text { (holm oak and cork oak) }\end{array}$ \\
\hline DO_SO_LO_TO & $\begin{array}{l}\text { DO } \\
\text { SO } \\
\text { LO } \\
\text { TO }\end{array}$ & DO_SO_LO & $\begin{array}{c}3.1 .1 .2 \\
(3.1 .3 .1 .2)\end{array}$ & $\begin{array}{l}\text { Forests dominated by other deciduous oaks (Turkey oak and/or downy } \\
\text { oak and/or Hungarian oak and/or sessile oak) }\end{array}$ \\
\hline$\overline{\text { HH_OBL }}$ & $\begin{array}{l}\mathrm{HH} \\
\mathrm{OBL}\end{array}$ & $\begin{array}{l}\mathrm{HH} \\
\mathrm{OBL}\end{array}$ & $\begin{array}{c}3.1 .1 .3 \\
(3.1 .3 .1 .3)\end{array}$ & $\begin{array}{l}\text { Forests dominated by other site-native broadleaves (mesophilous and } \\
\text { meso-thermophilous broadleaves as maple-ash, hop-hornbeam and } \\
\text { flowering ash) }\end{array}$ \\
\hline $\mathrm{RF}$ & $\mathrm{RF}$ & $\mathrm{RF}$ & $\begin{array}{c}3.1 .1 .6 \\
(3.1 .3 .1 .6)\end{array}$ & Forests dominated by hygrophytes \\
\hline NSP & NSP & NSP & 3.1 .1 .7 & $\begin{array}{l}\text { Forests and/or ex-plantations dominated by self-sown exotic } \\
\text { broadleaved species }\end{array}$ \\
\hline \multirow[t]{3}{*}{$\overline{\mathrm{SNC}}$} & SNC.1 & SNC.1 & $\begin{array}{c}3.1 .2 .1 \\
(3.1 .3 .2 .1)\end{array}$ & Forests dominated by Mediterranean pines and cypresses \\
\hline & SNC.2 & SNC.2 & $\begin{array}{c}3.1 .2 .3 \\
(3.1 \cdot 3.2 .3)\end{array}$ & Forests dominated by silver fir and/or spruce \\
\hline & SNC.3 & SNC.3 & $\begin{array}{c}3.1 .2 .2 \\
(3.1 .3 .2 .2)\end{array}$ & Forests dominated by oro-Mediterranean and Mountainous pines \\
\hline HSL_MSL_HMSL & $\begin{array}{l}\text { HSL } \\
\text { MSL } \\
\text { HMSL }\end{array}$ & HSL_MSL_HMSL & $\begin{array}{l}3.2 .23 .2 .3 \\
3.2 .4\end{array}$ & $\begin{array}{l}\text { Moorlands and bushes, sclerophyllous species areas, areas character- } \\
\text { ized by evolving woody and shrubby vegetation }\end{array}$ \\
\hline
\end{tabular}




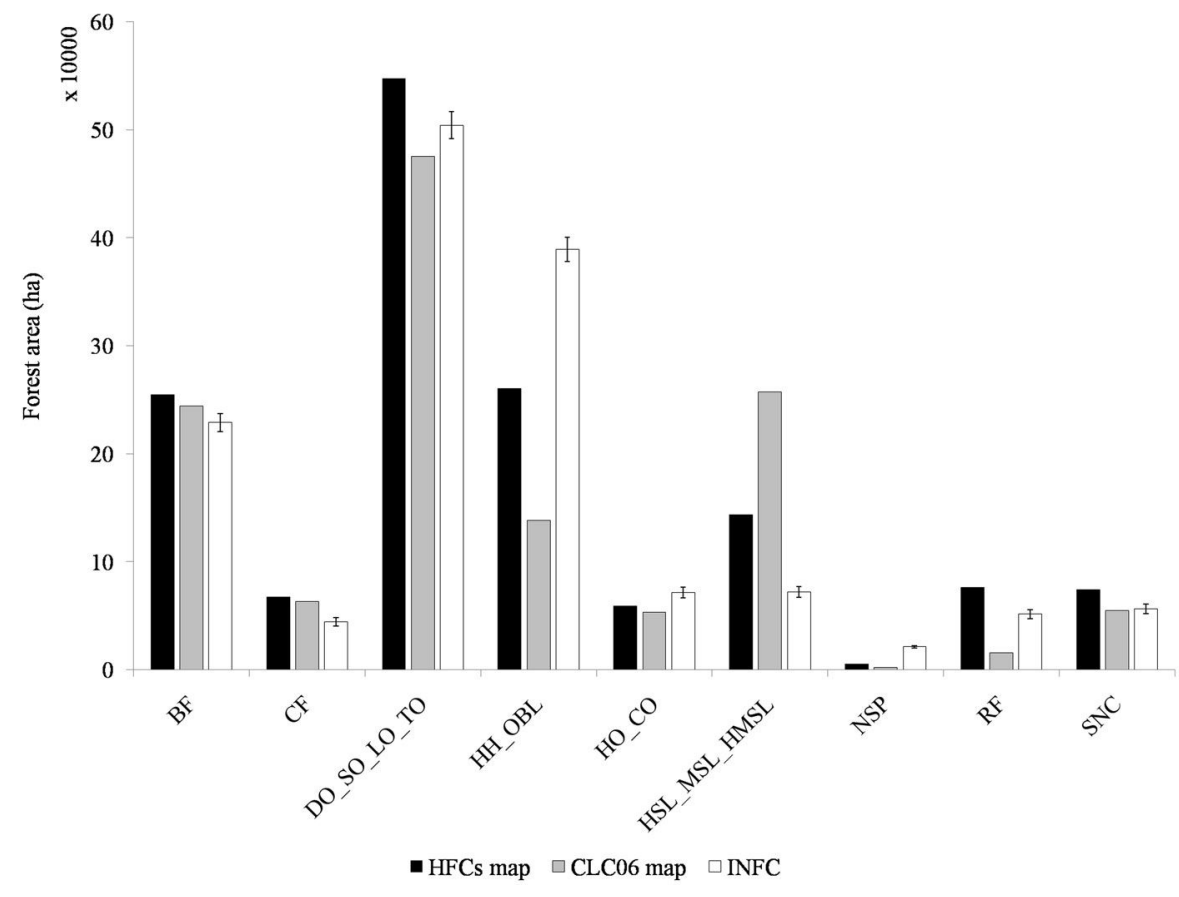

Fig. 5 - Forest area estimates (ha) from HFCs map, CLC06 map and INFC for each aggregated FC (see Appendix 1) and for each region in central Italy, separately. Error bars represent SE of INFC. See Appendix 1 for the HFCs label definition.

only represent $12 \%$ of the total area. The figures from the HFCs map were higher than INFC by $53 \%$, lower by $17 \%$ and higher by $31 \%$ respectively, while on the basis of CLC06 they were higher by $43 \%$, and lower by $25 \%$ and by $2 \%$ respectively.

The remaining four classes show more rele-

vant discrepancies. For other native broadleaved forests (HH-OBL), which represented $27 \%$ of the area, the HFCs and CLC06 figures were higher than INFC by $33 \%$ and $65 \%$, respectively. For OWL (HSL_MSL_HMSL) ( $5 \%$ of the total) HFCs map was higher than INFC for the $99 \%$, and the CLC06 was hi-

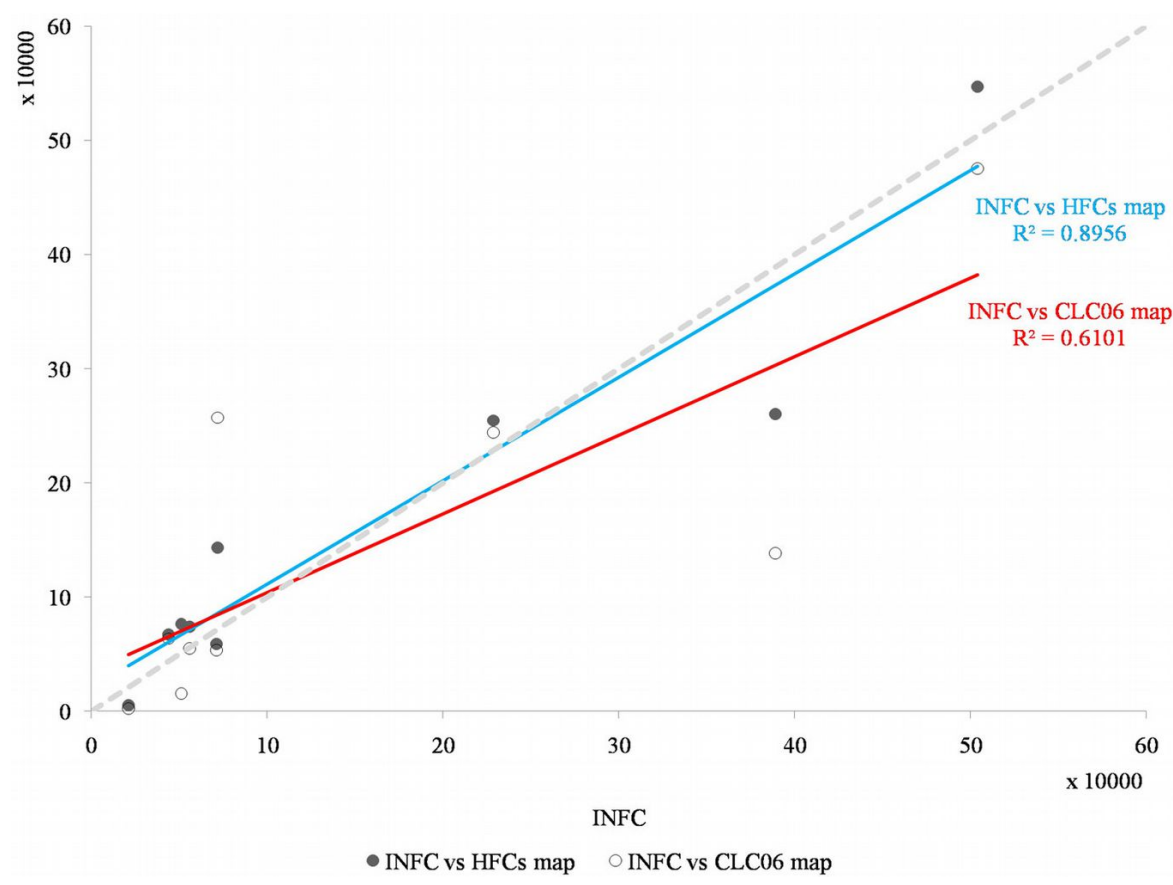

Fig. 6 - Comparison of HFCs and CLC06 forest area estimation against INFC, values in 104 ha. Each case is one of the aggregated forest macro-categories from Tab. 2 for each of the four Regions. Linear regression for CLC06 has $\mathrm{R}^{2}$ of 0.61 and of 0.89 for HFCs. gher for a $257 \%$, for riparian forests (RF) (3.5\% of the total) the figure from HFCs map was higher than INFC for a $49 \%$ but that from CLC06 was lower for a 70\%. Finally, for broadleaved plantations (NSP) (1.5\% of the total) HFCs and CLC06 figures were lower than INFC for a $75 \%$ and for a $90 \%$ respectively.

\section{Discussion and conclusions}

This contribution presents the harmonization test carried out to merge high resolution FTs maps available for four administrative Regions in Central Italy. The maps were independently developed referring to the period 2001-2007 and adopted the same FAO forest definition, and were created with the same methodology.

Following the approach proposed by Ståhl et al. (2011), harmonization bridges in the form of univocal correspondences among different FTs nomenclature systems, were used to develop a reference harmonized FTs nomenclature system (HFTNS) and bridges were then created between the HFTNS and the original FTs. After the harmonization, the forest area calculated on the basis of the different data sources (inventories and maps) was compared.

The proposed bottom-up approach appears to be feasible to classify and harmonize forest resources. Indeed, it guarantees the integrity and homogeneity of local FTs systems, as well as the best possible characterization of forest resources at regional level, maintaining the possibility of upscaling and downscaling information at the different spatial scales.

The HFTNS was aimed at solving current difficulties in exchanging forest data and information between forest managers, land planners and decision-makers at different scales and across different local administrations. For example, on the basis of the HFTs map, the automatic derivation of a FTs map for those protected areas which are across the regional administrative borders is now possible. Harmonized nomenclature systems should be used for multi-scale forest resources monitoring to limit lacks and mismatches in available data and information, also contributing to reduce the delay in the implementation of common rules, laws and guidelines at regional, national, and European levels.

Even if the methodology was successfully applied in the case study presented, some critical points in harmonizing FTs need to be highlighted. It is possible to create bridges between different FTs systems but it is more difficult to find correspondences between forest classification systems developed using different approaches. This was the case when we compared local FTs systems with the forest classes used by the INFC, which are not based on the "forest type" approach but 
are more simply based on dominant tree species. On the opposite, the identification of bridges between the four local FTs systems and the EFTs system developed by EEA was quite straightforward (Barbati et al. 2014).

In Italy, the "forest type" definition is based on a mix of physiognomic-structural characteristics and syntaxonomic and floristic information of the current stand conditions. Unlike phytosociological approach, the FTs approach is not based on the concep of climax or potential vegetation. Indeed, FTs represent only the actual forest vegetation resulting from the spatial and temporal scales and patterns of disturbances. Nonetheless, in most cases the correspondences are possible between the two approaches (FTs vs. phytosociological systems). This was clearly demonstrated in our test case with the quite simple and direct relationship we found between local FTs and the botanical approach used by Blasi (2010 - see Appendix 3 for the results).

The results obtained in forest area estimation by forest macro-categories (Fig. 5) indicate a general mismatch between the results from the different FCs maps (from HFCs and CLC06) when compared with INFC estimates. The agreement is higher for the two dominant FCs (deciduous oaks and beech), but the error is never below the $6 \%$, always more than the confidence interval of INFC.

When these results are analyzed separately for each Region (Fig. 5), we found that the Molise is the region where the area figures calculated for five out of the nine macro categories from the HFCs map (BF, HH-OBL, NSP, RF and SNC) are within the confidence intervals of INFC estimates. This result is obtained only in Abruzzo with CF and SNC and in Lazio and Marche with $\mathrm{HO}-\mathrm{CO}$ and SNC. These results can probably be explained considering that forest types dominated by deciduous oaks (mainly Quercus cerris and $Q$. pubescens) have frequently the presence of Acer and Fraxinus spp. too. Using photointerpretation, it is extremely difficult to discriminate these mesophylous formations and consequently obtain a good accuracy in mapping HH-OBL classes. The same problem probably occurred in mapping OWL (the HSL MSL HMSL macro category). We hope that the future availability of wall-to-wall Airborne Laser Scanning (ALS) data would contribute to a better discrimination of these formations on the basis of their canopy height.

When moving from FCs to forest / non-forest area estimation, the divergences between the different sources of information, including the pan-European mapping approaches, are reduced.

It is important to note that the agreement with INFC estimates is higher for HFCs maps than for CLC06 (Fig. 6). This is an ex- pected result since all the FTs maps available in the four Regions are implemented with a MMU and a minimum crown coverage that is coincident with the forest definition adopted by the INFC, while the CLC06 is implemented with a much greater MMU (25 ha for a reference scale of $1: 100000)$ and a crown cover threshold of $30 \%$ instead of $10 \%$. These results confirm previous conclusions related to the fact that the forest area calculated on the basis of CLC is usually underestimated when compared with national forest inventories estimates (Seebach et al. 2011).

Local differences in the investigated Regions are probably due to the quality of the different maps, a more in deep analysis of omission and commission errors could be possible only if the location of INFC sampling units would be available.

In the future we hope that the different forest monitoring and forest inventory programs currently active in Italy, as well as in Europe, will potentially converge on a common nomenclature system. The raw data acquired in forest inventories can be used to obtain forest area estimates on the basis of multiple nomenclature systems. Stakeholders and agencies responsible for forest inventories and land use/land cover mapping should join the efforts at national and local level in order to develop harmonized multiscale systems. The EFTs (Barbati et al. 2014) appear as a good basis to create a practical relationship between local forest management and country and European programs. The links we proposed between HFCs vegetation classes and CORINE biotopes (Appendix 3) could be extremely useful for forest managers involved in activities related to the application of SFM practices, for example within Natura2000 Network sites.

An attempt to establish bridging functions between HFCs and Natura2000 Network would be very interesting to highlight the implications of forest type mapping as well as for mapping Natura2000 Network habitats.

Recently for the first time Forest Europe/ UNECE/FAO (2011) presented forest area estimates based on the EFTs nomenclature system (Barbati et al. 2014); but at the moment a pan-European FTs map still does not exist, even considering that several tests were carried out to obtain a coniferous/ broadleaved map (Kempeneers et al. 2011) and a dominant tree species map (Brus et al. 2012).

Several possible and feasible solutions can be foreseen to derive a EFTs (sensu Barbati et al. 2014) map, if a new parallel project will not be funded: upgrading the Corine Land Cover including a more detailed FCs classification, following the example of Italy, or harmonizing and then merging local and national forest maps available in the dif- ferent Countries, or using the plot level information from NFIs, or a mix of the aforementioned approaches.

\section{Acknowledgements}

We would like to thank the colleagues at the Dipartimento di Bioscienze e Territorio of the University of Molise, for their support in data elaboration and analysis: Carmen Giancola, Daniela Tonti, Giovanni Santopuoli, Michele Minotti, Bruno Lasserre and Lorenzo Sallustio. We also thank Prof. Carlo Urbinati and Dr. Francesco Renzaglia from the Università Politecnica delle Marche for their support and help to analyze the FTs map of Marche region.

A special thanks to the anonymous reviewers who helped us in ameliorating a previous version of this manuscript, and to Daniel O. McInerney at Coillte (IR) for word revising and English check.

Finally, we thank Abruzzo, Lazio and Molise regional administrations for making available the FTs maps.

This work was partially carried out within the framework contract "Forests: fifth specific contract" between the European Environmental Agency, the European Forest Institute and the Italian Academy of Forest Sciences (contract no. EEA/NSV/10/004) and partially within the project "Development of innovative methods for forest ecosystems monitoring based on remote sensing", funded by the Italian Ministry of University and Research (PRIN 2012, grant no. 2012EWEY 2S, national scientific coordinator Prof. G. Chirici).

\section{References}

Amadei M, Bagnaia R, Laureti L, Lugeri F, Lugeri N, Feoli E, Dragan M, Fernetti M, Oriolo G (2003). Il Progetto Carta della Natura alla scala 1:250.000. Metodologia di realizzazione [The "map of nature" project at the scale of 1 : 250.000. Methodology]. Manuali e line guida APAT 17/2003, Agenzia per la Protezione dell'Ambiente e per i Servizi Tecnici - APAT, Rome, Italy, pp. 103. [in Italian]

Anderson JF, Hardy EE, Roach JT, Witmer RE (1976). A land use and land cover classification system for use with remote sensor data. US Geological Survey Professional Paper 964, US Government Printing Office, Washington, DC, USA, pp. 28.

Barbati A, Marchetti M, Chirici G, Corona P (2014). European Forest types and Forest Europe SFM indicators: tools for monitoring progress on forestbiodiversity conservation. Forest Ecology and Management 321: 145-147. - doi: 10.1016/j.foreco.2013.07.004

Blasi C (2010). La vegetazione d'Italia con carta delle Serie di Vegetazione in scala 1:500000 [The vegetation of Italy with the vegetation series map at the scale of 1:500.000]. Palombi Editore, Rome, Italy, pp. 539. [in Italian]

Brus DJ, Hengeveld GM, Walvoort DJJ, Goedhart 
PW, Heidema AH, Nabuurs GJ, Gunia K (2012). Statistical mapping of tree species over Europe. European Journal of Forest Research 131 (1) 145-157. - doi: 10.1007/s10342-011-0513-5

Canadian Forest Service (1995). Criteria and indicators for the conservation and sustainable management of temperate and boreal forests: the Montreal Process. The Canadian Forest Service, Hull, Quebec, Canada, pp. 13.

Chirici G, Fattori C, Cutolo N, Tufano M, Corona P, Barbati A, Blasi C, Copiz R, Rossi L, Biscontini D, Ribera A, Morgante L, Marchetti M (2014). Map of the natural and semi-natural environments and forest types map for the Latium region (Italy). Forest@ 11 (2): 65-71. [in Italian with English abstract] - doi: 10.3832/efor1204011

Corona P (2010). Integration of forest mapping and inventory to support forest management iForest 3: 59-64. - doi: 10.3832/ifor0531-003

Corona P, Barbati A, Tomao A, Bertani R, Valentini R, Marchetti M, Fattorini L, Perugini L (2012). Land use inventory as framework for environmental accounting: an application in Italy. iForest 5(1): 204. - doi: 10.3832/ifor0625-005

Corona P, Del Favero R, Marchetti M (2004). Stand-level forest type approach in Italy: experiences from the last twenty years. In: "Monitoring and indicators for Forest Biodiversity in Europe - from ideas to operationality" (Marchetti M ed). EFI Proceedings 51: 143-152.

Corona P, Marchetti M, Morgante L, Di Pietro R (2001). Cartografia sperimentale e prodromi di una tipologia dei boschi dell'Appennino Abruzzese [Experimental mapping and signs of a typology of the Apennine forests in Abruzzo region]. Annali Accademia Italiana Scienze Forestali, Firenze, Italy, pp. 175-242. [in Italian]

Del Favero R (2000). Biodiversità e indicatori nei tipi forestali del Veneto [Biodiversity and indicators for the forest types of Veneto region]. Regione Veneto, Direzione Regionale dell'Economia Montana e delle Foreste, Mestre, Venezia, Italy, pp. 335. [in Italian]

Del Favero R (2010). I boschi delle regioni dell'Italia centrale. Tipologia, funzionamento, selvicoltura [Forests in the Regions of central Italy]. CLUEP, Padova, Italy, pp. 425. [in Italian]

Del Favero R, Andrich O, De Mas G, Lasen C, Poldini L (1990). La vegetazione forestale del Veneto. Prodromi di tipologia forestale [Forest vegetation of Veneto region. Signs of forest typology]. Regione Veneto, Dipartimento Foreste, Mestre, Venezia, Italy, pp. 177.

Del Favero R, Lasen C (1993). La vegetazione forestale del Veneto [Forest vegetation of Veneto region] $\left(2^{\text {nd }} \mathrm{edn}\right)$. Progetto Editore, Padova, Italy, pp. 313. [in Italian]

EEA (2006). European forest types. Categories and types for sustainable forest management reporting and policy. Technical Report 9/2006,
European Environmental Agency, Office for Official Publications of the European Community, Luxembourg, pp. 111

FAO (2000). Global forest resource assessment 2000. Forestry Paper 140, FAO, Rome, Italy, pp. 479.

Fattorini L, Tabacchi G (2004). INFC, il disegno di campionamento [Italian National Forest Inventory, INFC. Sampling design]. Inventario Nazionale delle Foreste e dei Serbatoi Forestali di Carbonio, MiPAF - Direzione Generale per le Risorse Forestali Montane ed Idriche, Corpo Forestale dello Stato, CRA-ISAFA, Trento, Italy, pp. 36. [in Italian]

Forest Europe/UNECE/FAO (2011). State of Europe's forests 2011. Status and trends in sustainable forest management in Europe. FAO, Rome, Italy, pp. 337.

Garfì V, Marchetti M (2011). Tipi forestali e preforestali della regione Molise [Forest types of Molise region]. Edizioni Dell'Orso s.r.1., Alessandria, Italy, pp. 280. [in Italian]

Gasparini P, Tosi V, Di Cosmo L (2010). Italy. In: "National forest inventories: pathways for common reporting"'(Tomppo E, Gschwantner T, Lawrence M, McRoberts RE eds). Springer, Dordrecht, The Netherlands, pp. 311-331.

Hofmann A, Goretti D, Merendi GA, Tabacchi G, Vignoli M, Bernetti G (1998). L'inventario forestale. Boschi e macchie di Toscana [Forest inventory. Woodlands and shrublands of Tuscany region]. Giunta Regionale, Firenze, Italy, pp. 219. [in Italian]

INFC (2003). Guida alla classificazione della vegetazione forestale. Inventario nazionale delle Foreste e dei Serbatoi Forestali di Carbonio [Guide to the forest vegetation classification. Italian National Forest Inventory, INFC]. MiPAFDirezione Generale perle Risorse Forestali, Montane ed Idriche, Corpo forestale dello Stato, ISAFA, Trento, Italy, pp. 61. [in Italian]

IPLA (2001). I tipi forestali delle Marche: inventario e carta forestale della regione Marche [Forest types of Marche region: forest inventory and map of Marche region]. Regione Marche, Assessorato Agricoltura e Foreste, Ancona, Italy, pp. 252. [in Italian]

Kempeneers P, Sedano F, Seebach L, Strobl P, San-Miguel-Ayanz J (2011). Data fusion of different spatial resolution remote sensing images applied to forest-type mapping. IEEE Transactions on Geoscience and Remote Sensing 49 (12): 4977-4986. - doi: 10.1109/TGRS.2011.21 58548

Köhl M, Magnussen S, Marchetti M (2006). Sampling methods, remote sensing and GIS multiresources forest inventory. Springer, Heidelberg, Berlin, Germany, pp. 1-371.

McRoberts R, Tomppo E, Schadauer K, Vidal C, Stahl G, Chirici G, Lanz A, Cienciala E, Winter S,Smith B (2009). Harmonizing National Forest Inventories. Journal of Forestry 107 (4): 179-
187. [online] URL: http://www.ingentaconnect. com/content/saf/jof/2009/00000107/00000004/a rt00005

Pesaresi S, Biondi E, Casavecchia S, Catorci A, Foglia M (2007). Il geodatabase del sistema informativo vegetazionale delle Marche [The geodatabase of the vegetation information system of Marche region]. Fitosociologia 2, suppl. 1, pp. 95-101. [in Italian]

Romano D, Arcarese C, Bernetti A, Caputo A, Cóndor RD, Contaldi M, Lauretis R, Di Cristofaro E, Federici S, Gagna A, Gonella B, Lena F, Liburdi R, Taurino E, Vitullo M (2011). Italian greenhouse gas inventory 1990-2009. National inventory report. ISPRA, Rome, Italy, pp. 353.

Sambucini V, Marinosci I, Bonora N, Chirici G (2010). La realizzazione in Italia del Progetto europeo Corine Land Cover 2006 [The implementation of the Corine Land Cover 2006 European project in Italy]. ISPRA Rapporti 131/2010, Ispra, VA, Italy, pp. 49. [in Italian] Seebach LM, Strobl P, San Miguel-Ayanz J, Gallego J, Bastrup-Birk A (2011). Comparative analysis of harmonized forest area estimates for European countries. Forestry 84: 285-299. - doi: 10.1093/forestry/cpr013

Ståhl G, Cienciala E, Chirici G, Lanz A, Vidal C, Winter S, McRoberts RE, Rondeux J, Schadauer $\mathrm{K}$, Tomppo E (2011). Bridging national and reference definitions for harmonising forest statistics. Forest Science 58: 214-223. - doi: 10.5849/ forsci.10-067

Tabacchi G, De Natale F, Di Cosmo L, Floris A, Gagliano C, Gasparini P, Genchi L, Scrinzi G, Tosi V. (2007). Le stime di superficie 2005 Parte 1. Inventario Nazionale delle Foreste e dei Serbatoi Forestali di Carbonio [Forest area estimates 2005 - Section 1. Italian National Forest Inventory, INFC]. MiPAF - Corpo Forestale dello Stato - Ispettorato Generale, CRA - ISAFA, Trento, Italy, pp. 1-413. [in Italian]

\section{Supplementary Materials}

Appendix 1 - HFCs and HFTs at regional level in Central Italy, and related correspondences to regional FTs nomenclatures in Central Italy.

Link: Vizzarri_1133@supp1001.pdf

Appendix 2 - Correspondences among HFCs, the INFC FCs and Sub-Cs, the EFTs, and the CLC06 nomenclature systems. Link: Vizzarri_1133@supp1002.pdf

Appendix 3 - Correspondences among HFCs, vegetation classes (at national level, sensu Blasi 2010), and CORINE biotopes (sensu Amadei et al. 2003).

Link: Vizzarri_1133@supp1003.pdf 